\title{
The Neuronal Adhesion Protein TAG-1 Is Expressed by Schwann Cells and Oligodendrocytes and Is Localized to the Juxtaparanodal Region of Myelinated Fibers
}

\author{
Maria Traka, ${ }^{1}$ Jeffrey L. Dupree, ${ }^{2}$ Brian Popko, ${ }^{2}$ and Domna Karagogeos ${ }^{1,3}$ \\ ${ }^{1}$ Department of Basic Science, University of Crete Medical School, Heraklion 71110, Crete, Greece, ${ }^{2}$ Neuroscience \\ Center, University of North Carolina at Chapel Hill, Chapel Hill, North Carolina 27599, and 3/nstitute of Molecular Biology \\ and Biotechnology, Foundation for Research and Technology, Heraklion 71110, Crete, Greece
}

The neural cell adhesion molecule TAG-1, which is a glycosylphosphatidylinositol-linked member of the lg superfamily, is expressed by various neuronal populations in the developing CNS and PNS. We demonstrate here that Schwann cells and oligodendrocytes also express TAG-1. In the PNS, TAG-1 is detected in ensheathing Schwann cells early postnatally and is maintained throughout adulthood. In mature myelinated fibers of the CNS and PNS, TAG-1 is localized to the juxtaparanodal region. The CNS of the UDP-galactose ceramide galactosyl transferase ${ }^{-1-}\left(\mathrm{CGT}^{-/-}\right)$mouse mutants, which do not synthesize the abundant galactolipids of myelin, display severely disrupted axoglial interactions at the paranodal region. In contrast, axoglial interactions in the PNS of these mutants are less affected. Interestingly, TAG-1 localization is completely undetected in myelinated fibers of the CNS. In the PNS of these mutants, TAG-1 abnormally localizes in the paranodal region. These data raise the intriguing possibility that TAG-1 localization in the juxtaparanodal area mediates, or at least requires, the axoglial contact normally displayed in this region. The abnormal localization of TAG-1 in the CGT mutants might contribute to the disrupted axoglial interactions observed in these animals.

Key words: glia; TAG-1; ensheathing; potassium channels; juxtaparanode; galactolipid; axoglial interactions
The organization of distinct domains in myelinated fibers in both the CNS and the PNS seems to be strongly dependent on the interactions between the axon and the glial cells. These domains, which consist of the node of Ranvier and the paranodal and juxtaparanodal regions and the internode, ensure the rapid propagation of the action potential along myelinated fibers. The molecular components that mediate the axoglial interactions critical for the formation and maintenance of these regions are poorly understood. Lately, a number of studies have shown that different domains of myelinated fibers contain a distinct set of adhesion molecules that are thought to interact with extracellular matrix molecules and glial cell receptors (for review, see Peles and Salzer, 2000; Pedraza et al., 2001; Brophy, 2001).

The periodic structure of the node of Ranvier, which is exposed to the extracellular milieu, contains a high concentration of voltage-gated sodium channels existing as a complex with anky$\operatorname{rin}_{\mathrm{G}}$ and the Ig superfamily (IgSF) molecules $\mathrm{Nr}-\mathrm{CAM}$ and neurofascin (Davis et al., 1996). Recently, paranodin/contactin-

\footnotetext{
Received July 12, 2001; revised Feb. 4, 2002; accepted Feb. 4, 2002.

This work has been supported by the Greek Ministry of Education (Grant EPEAEK 1092), the Greek Secretariat for Research and Technology (Grant PENED 99ED329), the European Union Biotechnology Grant 980329 (D.K.), by the National Institutes of Health Grant NS27336 (B.P.), and by National Multiple Sclerosis Society Grant PP0770 (J.L.D.). We thank J. A. Girault, T. Jessell, S. Morton, F. Rathjen, G. Rougon, and M. Schachner for reagents. We thank Phaedra Xekardaki who helped us in preparing the figures of this paper, Giannis Haralabopoulos for his help in immunohistochemical experiments, and Rania Pavlou and Kostas Theodorakis for their advice on RT-PCR and Southern blot analysis. We also thank Drs. R. Matsas and D. Thomaidou of the Hellenic Pasteur Institute for use of the confocal facility.

Correspondence should be addressed to Dr. Domna Karagogeos, University of Crete Medical School and Institute of Molecular Biology and Biotechnology, P. O. Box 1527, Vassilika Vouton, Heraklion 71110, Crete, Greece. E-mail: karagoge@imbb.forth.gr.

Copyright (C) 2002 Society for Neuroscience $\quad 0270-6474 / 02 / 223016-09 \$ 15.00 / 0$
}

associated protein (Caspr), a member of the neurexin superfamily, and the adhesion molecules NF-155 and contactin/F3, members of the IgSF, have been identified as components of septate-like paranodal junctions where the axolemma is in close contact with the myelinating cell membrane (Einheber et al., 1997; Menegoz et al., 1997; Rios et al., 2000; Tait et al., 2000). These junctions probably restrict the lateral diffusion of the voltage-gated sodium channels into the paranodal-juxtaparanodal region and retard ionic movements (for review, see Salzer, 1997). Moreover, these sites could mediate bidirectional signaling between the axon and myelinating glial cells. Finally the paranodal axoglial junctions control the distribution of Shaker-type Kv1.1 potassium channels in the juxtaparanode and inhibit their exposure to the extracellular milieu (Dupree and Popko, 1999). The potassium channels are present at high concentration in the juxtaparanode and are associated with Caspr2, another member of the neurexin superfamily (Poliak et al., 1999).

The adhesion molecule TAG-1, an IgSF member, has previously been detected only in various neuronal populations of the CNS and PNS during embryonic development (Dodd et al., 1988; Furley et al., 1990; Karagogeos et al., 1991). TAG-1 exists both as a glycosylphosphatidylinositol (GPI)-linked cell surface isoform and as a released form.

In this report we present evidence that TAG-1 is also expressed in ensheathing and myelinating Schwann cells and in oligodendrocytes. In addition, we demonstrate that TAG-1 is localized to the juxtaparanodal region of myelinated fibers in both the CNS and PNS. Moreover, we show that TAG-1 localization in myelinated fibers is disrupted in mice deficient in the major galactolipids of myelin (CGT $\left.{ }^{-/}\right)$(Coetzee et al., 1996), which display severely altered axoglial interactions at the paranodal region (Dupree et al., 1998). These data raise the intriguing possibility that TAG-1 
plays a role in regulating axoglial interactions in the juxtaparanodal region of myelinated fibers.

\section{MATERIALS AND METHODS}

Antibodies. Both monoclonal and polyclonal antibodies to TAG-1 (Yamamoto et al., 1986; Dodd et al., 1988) were used. The 4D7 monoclonal antibody was used for immunolabeling of cultured cells, whereas polyclonal antibodies were used for Western blotting and for immunohistochemistry. Polyclonal antisera to neural cell adhesion molecule (NCAM) and paranodin/Caspr were generously provided by Dr. G. Rougon, (Developmental Biology Institute, Marseille, France) and by Dr. Jean-Antoine Girault (Institut National de la Sante et la Recherche Medicale, Paris, France), respectively. A monoclonal antibody to myelinassociated glycoprotein (MAG) was kindly provided by Dr. M. Schachner (Center for Molecular Neurobiology, University of Hamburg, Germany). L1 was detected either by the monoclonal antibody 69A1 (Pigott and Davies, 1987) or by a polyclonal antibody (Rathjen and Schachner, 1984). Antibodies to glial fibrillary acidic protein (GFAP) (Sigma, St. Louis, MO), S-100 (Dako, Carpinteria, CA), sodium channel (Sigma), Kv1.1 potassium channel (monoclonal; Upstate Biotechnology, Lake Placid, NY) and adenomatous polyposis coli protein (APC) (Oncogene, Darmstadt, Germany) were used. Goat anti-rabbit Cy3 or FITC and goat anti-mouse $\mathrm{Cy} 3$ or FITC were used (Jackson ImmunoResearch, West Grove, PA)

In situ hybridization. Riboprobes were generated using the full-length TAG-1 cDNA (Furley et al., 1990) as a template. We used digoxigeninlabeled antisense and sense probes to hybridize $10-\mu \mathrm{m}$-thick tissue sections from hindlimbs of embryonic day 16 (E16) and E18 rat, adult rat sciatic nerves, and $200 \mu \mathrm{m}$ thick sections from adult spinal cord. In situ hybridization was performed as described in Blanchard et al. (1996) with the following modifications: frozen sections from fixed hindlimbs and fresh frozen adult sciatic nerves were dried at room temperature (RT) at least for $30 \mathrm{~min}$; adult sciatic nerves were treated for $15 \mathrm{~min}$ in $5 \mu \mathrm{g} / \mathrm{ml}$ proteinase- $\mathrm{K}$ at $37^{\circ} \mathrm{C}$; dehydrated, delipidated with chloroform, partially rehydrated, and air dried. In situ hybridization in adult spinal cord sections was performed as described in Bally-Cuif and Wassef (1994). Slides were viewed and photographed on a Zeiss Axioskop.

Schwann cell cultures. Single cells from sciatic nerves from postnatal day 5 (P5) rats were prepared and maintained in culture as described previously (Kreider et al., 1981).

Immunohistochemistry. Rat or mouse sciatic nerves were dissected and fixed in $2 \%$ paraformaldehyde for $30 \mathrm{~min}$ at RT. Also, cervical regions of spinal cords and sciatic nerves from 30 -d-old CGT ${ }^{-1-}$ mice and their wild-type littermates were dissected and were processed as above. Sciatic nerves were teased apart to yield single fiber preparations, air-dried overnight at RT, and kept at $-80^{\circ} \mathrm{C}$. For immunostaining, teased fibers and spinal cord $10-12 \mu \mathrm{m}$ frozen sections were used. Especially for immunostaining at postnatal sciatic nerve, we used both teased fibers and $10 \mu \mathrm{m}$ frozen sections. All tissue samples were incubated in $-20^{\circ} \mathrm{C}$ acetone for 10-20 min. Specimens were blocked for $1 \mathrm{hr}$ at RT in PBS containing $10 \%$ fetal calf serum (FCS), $5 \%$ fish gelatin, $0.1 \%$ Triton $\mathrm{X}-100$, and incubated overnight with primary antibodies diluted in PBS containing $1 \% \mathrm{FCS}, 5 \%$ fish gelatin, $0.1 \%$ Triton $\mathrm{X}-100$, at $4^{\circ} \mathrm{C}$. Negative controls included incubation of sections without primary antibodies or with rabbit serum and processed regularly. Especially for double labeling for TAG-1 and paranodin/Caspr, teased fibers or sections were labeled sequentially, because both of antibodies we used were rabbit polyclonals. Images were acquired by a Leica (Nussloch, Germany) TCS-NT laserscanning microscope using a $40 \times$ or a $63 \times$ oil objective. Schwann cells grown on coverslips, for $4 \mathrm{~d}$ in vitro (DIV) were immunolabeled as described previously (Dodd et al., 1988; Karagogeos et al., 1991). Coverslips were mounted on microscope slides in Mowiol mounting medium (Calbiochem, Darmstadt, Germany).

Image analysis. We collected a $z$-series of optical sections in the $x y$ plane of the tissue in a Leica TCS-NT laser-scanning microscope. The complete set of sections showing the overlay (yellow) of the two channels were further used to view three-dimensional structural information about the specimen. We acquired cross-sectional slices through the image volume in the $x z$ and $y z$ plane by using the Ortho slice tool in the Leica PowerScan software. Final image reconstruction from the crosssectional slices was performed in Adobe Photoshop (Adobe Systems, San Jose, CA).

Isolation of myelin fractions. Spinal cords from adult mice were quickly dissected and frozen for myelin isolation (Norton and Poduslo, 1973; Huber et al., 1994). Briefly the tissue was homogenized in $0.32 \mathrm{M}$ sucrose and 2 mM EGTA, pH 7.5, layered on 0.85 м sucrose and 2 mM EGTA, and centrifuged for $1 \mathrm{hr}$ at $4^{\circ} \mathrm{C}$ in a SW28 Beckman rotor at 28,000 rpm. The interface was collected and osmotically shocked in distilled water. The crude myelin extract was processed to a second discontinuous sucrose gradient, and after centrifugation the floated myelin at the sucrose interface was collected. Sucrose was washed out, and the resulting pellets were resuspended in a minimal volume of buffer at $4{ }^{\circ} \mathrm{C}$ containing $50 \mathrm{~mm}$ Tris-HCl, pH 7.2, $1 \%$ NP-40, $1 \mathrm{~mm}$ PMSF, $5 \mathrm{~mm}$ EGTA, and $2 \mu \mathrm{g} / \mathrm{ml}$ each of leupeptin and aprotinin, and stored at $-80^{\circ} \mathrm{C}$ till used.

Western blot analysis. P5 sciatic nerves and P7 cerebellum were quickly dissected from deeply anesthetized rats, frozen in dry ice, and stored at $-80^{\circ} \mathrm{C}$ until used. The tissue was homogenized in fresh buffer $\left(\right.$ at $\left.4^{\circ} \mathrm{C}\right)$ containing $50 \mathrm{~mm}$ Tris-HCl, pH 7.2, $1 \%$ NP-40, $1 \mathrm{~mm}$ PMSF, $5 \mathrm{~mm}$ EGTA, and $2 \mu \mathrm{g} / \mathrm{ml}$ leupeptin and aprotinin. Samples were centrifuged for $20 \mathrm{~min}$ at $10,000 \times \mathrm{g}$ at $4^{\circ} \mathrm{C}$, and the supernatants were isolated for further analysis. Protein extracts from Schwann cells after 4 DIV were prepared with the same homogenization buffer from culture dishes, and the supernatants were isolated again. The total protein in each sample was quantified with the Bradford Bio-Rad (Hercules, CA) kit. The samples were run in an SDS-PAGE gel and further treated as described before (Dodd et al., 1988; Karagogeos et al., 1991), except the ECL method (Amersham, Freiburg, Germany) was used for revelation of the protein bands.

$R N A$ isolation and reverse transcription. Sciatic nerves from P5 rats, adult rats, and cerebellum from $\mathrm{P} 7$ rats were removed and quickly frozen on dry ice. Total RNA was extracted using the guanidinium thiocyanate extraction procedure (Chirgwin et al., 1979). Total RNA was extracted from Schwann cells after 4 DIV using the RNAzol method (Cinna/ Biotecx, Houston, TX)

For reverse transcription, $\leq 5 \mu \mathrm{g}$ of total RNA was used in a $20 \mu \mathrm{l}$ reaction containing $250 \mathrm{ng}$ random hexamers, $20 \mathrm{~mm}$ Tris- $\mathrm{HCl}, \mathrm{pH} 8.4$, $50 \mathrm{~mm} \mathrm{KCl}, 2.5 \mathrm{~mm} \mathrm{MgCl}_{2}$, and $0.05 \mathrm{~mm}$ each deoxyribonucleoside triphosphate (dNTP), $0.01 \mathrm{M}$ DTT, and $200 \mathrm{U}$ of Superscript II reverse transcriptase, and the manufacturer's protocol (Superscript II RT-PCR System from Invitrogen, San Diego, CA) was followed as recommended.

PCR and Southern blotting. Ten percent of the first-strand reaction was used as a template in a $50 \mu \mathrm{l}$ reaction containing PCR buffer, $1.5 \mathrm{~mm}$ $\mathrm{MgCl}_{2}, 0.2 \mathrm{~mm}$ each dNTP, $0.5 \mu \mathrm{M}$ of each upstream and downstream primers, and $2.5 \mathrm{U}$ of Taq DNA polymerase (Roche, Mannheim, Germany). The PCR reaction was cycled through one cycle at $94^{\circ} \mathrm{C}$ for $4 \mathrm{~min}$, 30 rounds at $94^{\circ} \mathrm{C}$ for $1 \mathrm{~min}$; at $55^{\circ} \mathrm{C}$ for $1 \mathrm{~min}$; at $72^{\circ} \mathrm{C}$ for $1 \mathrm{~min}$; and a final extension at $72^{\circ} \mathrm{C}$ for $1 \mathrm{~min}$. The following primer pairs were used: for rat TAG-1 sense 5'-GACACACGCCAGGA AAAAGG-3', antisense 5'-TGGGGAACTCGTTGAGGAGC-3', which amplify a 524 bp product. For normalization of mRNA quantity that was used in each reaction, the internal control cyclophilin mRNA was coamplified using the following primers: sense 5'-ACGGAGAGAAATTTGAGG-3', antisense 5'GGGAATGAGGAAAATATGG-3' which amplify a 400 bp product. The PCR products were blotted and hybridized with a 2500 bp ${ }^{32} \mathrm{P}$ random-labeled DNA fragment derived after digestion of TAG-564 cDNA clone (Furley et al., 1990) with KpnI restriction enzyme.

\section{RESULTS}

\section{TAG-1 is expressed by Schwann cells during development and in the adult}

In situ hybridization and immunohistochemistry were performed on hindlimb sections of rat embryos at critical time points of Schwann cell development, namely at E16 (when Schwann cell precursors emerge from neural crest cells) and at E18 (when immature Schwann cells are formed by Schwann cell precursors) (for review, see Mirsky and Jessen, 1996). No signal for TAG-1 mRNA or protein was detected at either stage (data not shown). In contrast, in the adult sciatic nerve, TAG-1 mRNA (Fig. 1 $A, B$ ) was detected in cells with the characteristic spindle shape typical of Schwann cells. Western blot analysis (Fig. 1C) was used to test whether the biochemical profile of the TAG-1 protein is the same in Schwann cells as in neurons. A single $135 \mathrm{kDa}$ band characteristic of TAG-1 protein appeared in cell extracts of P5 (Fig. 1C, lane 1) sciatic nerve.

As an independent way of demonstrating the expression of 

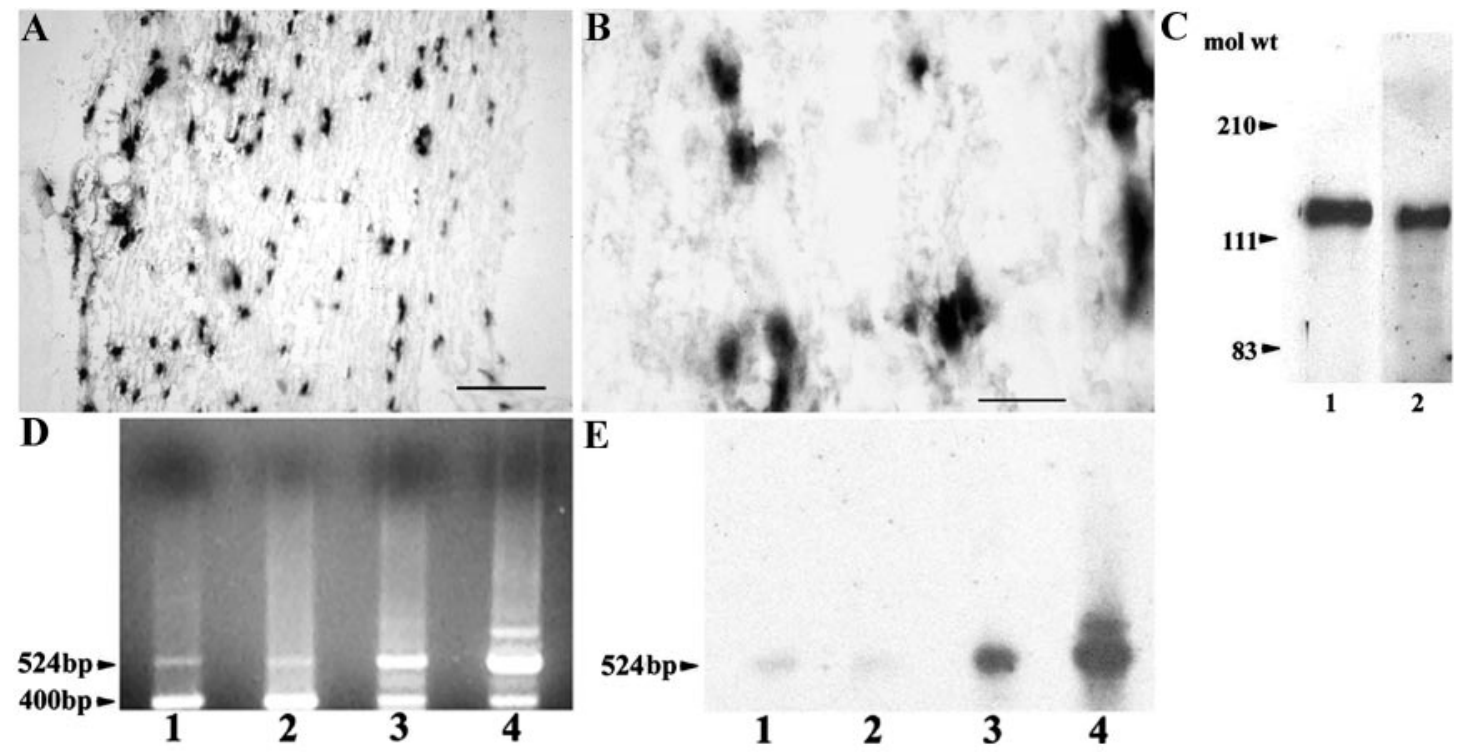

$\mathbf{E}$
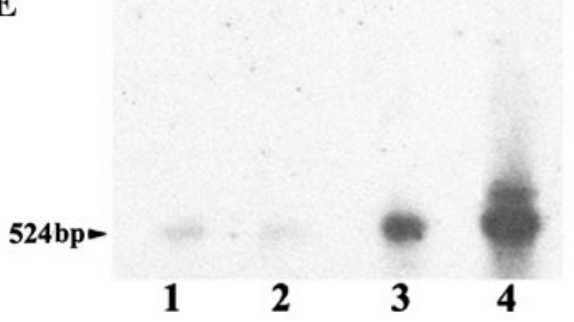

Figure 1. TAG-1 is expressed by Schwann cells during development and in the adult. $A$, In longitudinal sections from adult sciatic nerve, TAG-1 mRNA is detected in cells with the typical spindle shape morphology of Schwann cells (higher magnification, $B$ ). $C$, Western blot analysis shows that TAG-1 is expressed in whole protein extracts from P5 sciatic nerve (lane $1,30 \mu \mathrm{g}$ ) as a $135 \mathrm{kDa}$ band. Protein extract from postnatal cerebellum was loaded in lane $2(10 \mu \mathrm{g})$. D, A rat TAG-1-specific 524 bp band is detected by reverse transcription-PCR analysis in total RNA isolated from Schwann cells after 4 DIV (lane 1), P5 sciatic nerve (lane 2), adult sciatic nerve (lane 3), and postnatal cerebellum (lane 4 ). A cyclophilin 400 bp band was used to normalize the mRNA levels in each sample. $E$, The gel in $D$ was hybridized with a $2.5 \mathrm{~kb}{ }^{32} \mathrm{P}$-labeled $K p n \mathrm{I}-K p n \mathrm{I}$ DNA fragment of TAG-564 plasmid (Furley et al., 1990). Scale bars: $A, 10 \mu \mathrm{m} ; B, 5 \mu \mathrm{m}$.

TAG-1, RT-PCR experiments were performed using total RNA from Schwann cells after $4 \mathrm{~d}$ in culture (4 DIV), P5, and adult sciatic nerves (Fig. 1D, lanes 1-3, respectively). A TAG-1-specific $524 \mathrm{bp}$ fragment was isolated that hybridized to a $2.5 \mathrm{~kb}{ }^{32} \mathrm{P}$ labeled TAG-1 probe, further confirming the presence of TAG-1 message in the previous samples (Fig. 1E, lanes 1-3). TAG-1 message seemed to be present at comparable levels in Schwann cells after 4 DIV and in P5 sciatic nerve (lanes 1, 2), but both were less abundant when compared with adult sciatic nerve levels (lane 3). The qualitative estimates were done by taking into account the levels of the $400 \mathrm{bp}$ cyclophilin product, which was simultaneously amplified in each condition (Fig. 1D).

\section{Distribution of TAG-1 in Schwann cells during development}

TAG-1 was expressed in cultures of Schwann cells from P5 sciatic nerves. The cultures examined were in a nonproliferative state because they were densely seeded at $>20 \times 10^{3}$ cells per coverslip (Morgan et al., 1991). After 4 DIV, TAG-1 was detected on the surface of living Schwann cells with the characteristic punctate pattern (Fig. $2 A$ ) that it also exhibits on the surface of neuronal cells (Karagogeos et al., 1991). TAG-1 was also present as a released form, as is the case in dorsal root ganglion cell cultures (data not shown; Karagogeos et al., 1991). Almost all cells $(\sim 99 \%)$ in these cultures were S-100-positive (Fig. 2C), and they expressed NCAM on their surface and GFAP in their cytoplasm (Fig. 2E, $G$, respectively), indicative of a nonmyelinating phenotype (for review, see Jessen and Mirsky, 1991). We further analyzed the developmental profile of TAG-1 in sciatic nerve in vivo by immunohistochemistry on P6 sciatic nerve sections and teased fibers. Ensheathing Schwann cells expressed TAG-1 (Fig. $3 A$ ), as judged by its colocalization with L1 (Fig. $3 B, C$ ). In contrast, myelinating Schwann cells did not express TAG-1 at this stage because it was not detected on myelin-associated glycoprotein (MAG)-positive Schwann cells on P6 sciatic nerve sections
(Fig. 3D). Moreover, we did not detect any TAG-1 on P6 myelinated fibers, whereas paranodin/Caspr, an axolemmal protein, is already clustered to the paranode (Fig. $3 E$ ).

\section{TAG-1 is expressed in the juxtaparanodal region of PNS myelinated fibers in the adult}

Next we analyzed the distribution of TAG-1 in Schwann cells from adult sciatic nerve. In teased nerve fibers, TAG-1 was detected in myelinated fibers where it was localized in the region juxtaposed to the node of Ranvier (Fig. 4A). In unmyelinated fibers, TAG-1 was still expressed by ensheathing Schwann cells (Fig. 4B), where it was colocalized with L1 (Fig. 4C,D). In addition, TAG-1 was detected in the Schmidt-Lanterman incisures of myelinated fibers (Fig. 4E). To further analyze the distribution of TAG-1 in myelinated fibers (Fig. $4 F$ ), we performed double labeling for MAG, which is expressed in the paranodal loops of mature myelinated fibers (Martini and Schachner, 1986). The TAG-1 signal was adjacent to, but did not overlap MAG, indicating a juxtaparanodal localization (Fig. 4G). In addition, TAG-1 does not overlap with the funnel-shaped incisures labeled for MAG, but it coincides with the smallest diameter of the funnel, which is closest to the axon (Fig. 4H). Therefore, we suggest that TAG-1 is probably localized in the inner aspect of incisures that appose the axonal membrane. TAG-1 clustering in the juxtaparanodal region is further confirmed by double-labeling experiments for TAG-1 with Shakertype Kv1.1 potassium channels, which are clustered in the juxtaparanodal axolemma of myelinated fibers (Wang et al., 1993). These experiments showed that TAG-1 (Fig. 5A) has the same distribution with axolemmal Kv1.1 potassium channels (Fig. $5 B$ ) in myelinated fibers (Fig. $5 C$ ). In the internodal region TAG-1 also overlaps significantly with Kv1.1 potassium channels (Fig. $5 C$ ), which appose the innermost aspect of incisures and inner mesaxon of the myelin sheath (Arroyo et al., 1999). To distinguish a glial versus neuronal origin of TAG-1 expression in the 

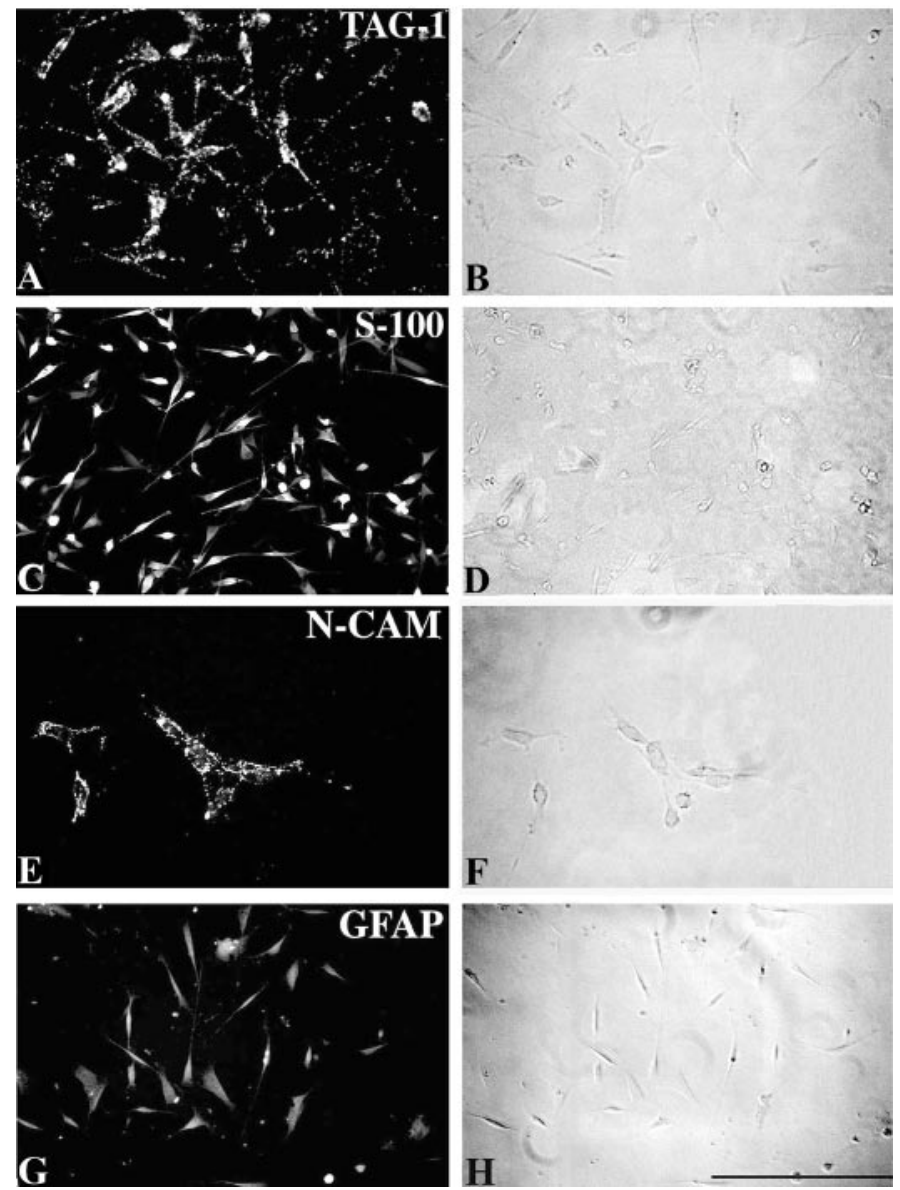

Figure 2. TAG-1 is expressed in Schwann cells in vitro. A, Schwann cell cultures, derived from P5 sciatic nerve, express TAG-1 on their surface in a punctate pattern, after 4 DIV. $C$, At this time point almost all the cells express the $\mathrm{Ca}^{2+}$-binding protein S-100, NCAM on their surface $(E)$, and GFAP intracellularly $(G)$. $B, D, F$, and $H$ are the phase-contrast optics of $A, C, E$, and $G$. Scale bar, $25 \mu \mathrm{m}$.

juxtaparanode, we used highly magnified confocal images (Fig. $5 D)$ that showed TAG-1 colocalization with Kv1.1 potassium channels (Fig. $5 E$ ) in this region (Fig. $5 F$ ). We examined crosssectional slices through the image volume showing TAG-1/Kv1.1 overlap in the $x z$ and $y z$ planes (Fig. $5 G, H$, respectively) to obtain three-dimensional structural information about the accumulation of TAG-1 in the juxtaparanodal region. The relative planes of the $x z$ and $y z$ cross-sectional slices are represented in Figure 5I. In both the $x z$ slices (Fig. 5G1,G2,G3) and $y z$ slices (Fig. 5H1,H2,H3) acquired, TAG-1 and potassium channels did not show significant colocalization. Therefore, we suggest that TAG-1 is most likely present in the Schwann cell myelin membrane that apposes the juxtaparanodal axolemma.

\section{TAG-1 is expressed by oligodendrocytes and accumulates at the juxtaparanodal region}

To determine whether oligodendrocytes, the myelinating glia of the CNS, express TAG-1 we performed in situ hybridization and immunohistochemical analysis on both white and gray matter regions of adult spinal cord sections. TAG-1 mRNA was detected in small cells of the white matter region that likely correspond to oligodendrocytes (Fig. 6A,B). Moreover, in the ventral horns of the spinal cord, large spindle-shaped cells with classic motor neuron morphology were intensely positive for
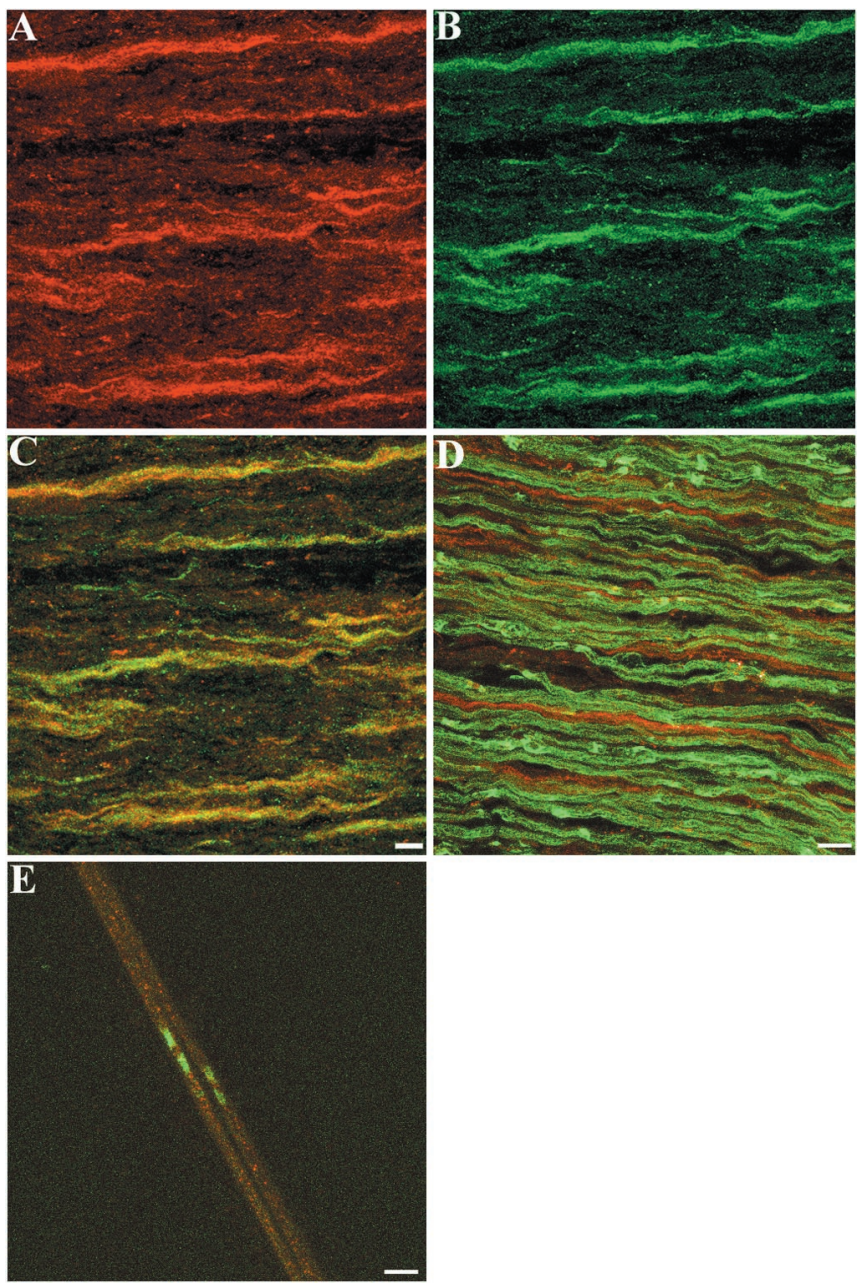

Figure 3. Distribution of TAG-1 in Schwann cells of postnatal sciatic nerve. $A$, On P6 sciatic nerve sections, TAG-1 is expressed by ensheathing Schwann cells detected by $\mathrm{L} 1$ labeling $(B$, green $) . C$ is the combined image of $A$ and $B$ that shows that both channels overlap (yellow). $D$, On P6 sciatic nerve sections, myelinating Schwann cells detected by MAG labeling (green) are negative for TAG-1 (red), which appears in ensheathing Schwann cells only. E, At P6 myelinated fibers, TAG-1 (red) does not appear to be clustered, whereas in the paranodal region paranodin/Caspr is already detected (green). $A-C$, Eleven images, $0.6 \mu \mathrm{m}$ apart; $D$, nine images, $0.9 \mu \mathrm{m}$ apart; $E$, seven images, $0.6 \mu \mathrm{m}$ apart. Scale bar, $10 \mu \mathrm{m}$.

TAG-1 mRNA (Fig. 6A,B). These neurons also appear to express the TAG-1 protein by immunohistochemistry (data not shown). In white matter, round to oval cells frequently oriented in rows, suggestive of myelinating oligodendroglia, were also TAG-1-positive (Fig. 6C). Using a monoclonal antibody directed against the APC protein, a marker of oligodendrocytes (Bhat et al., 1996), we verified that TAG-1 was actually expressed by oligodendrocytes (Fig. 6D). TAG-1 was already detected in oligodendrocytes in P12 spinal cord (data not shown). TAG-1 was also detected in small clusters in white matter of adult spinal cord (Fig. $6 E$ ), and by double labeling of these sections for the axolemmal protein paranodin/Caspr (Fig. 6F), we determined that TAG-1 was concentrated in the juxtaparanodal region of CNS myelinated fibers. A number of neuronal cells also express TAG-1 in the adult spinal cord (shown above) (Fig. 6A,B), so a neuronal origin of TAG-1 in the juxtaparanode cannot be excluded. In an effort to address this issue we performed Western blot analysis for TAG-1 

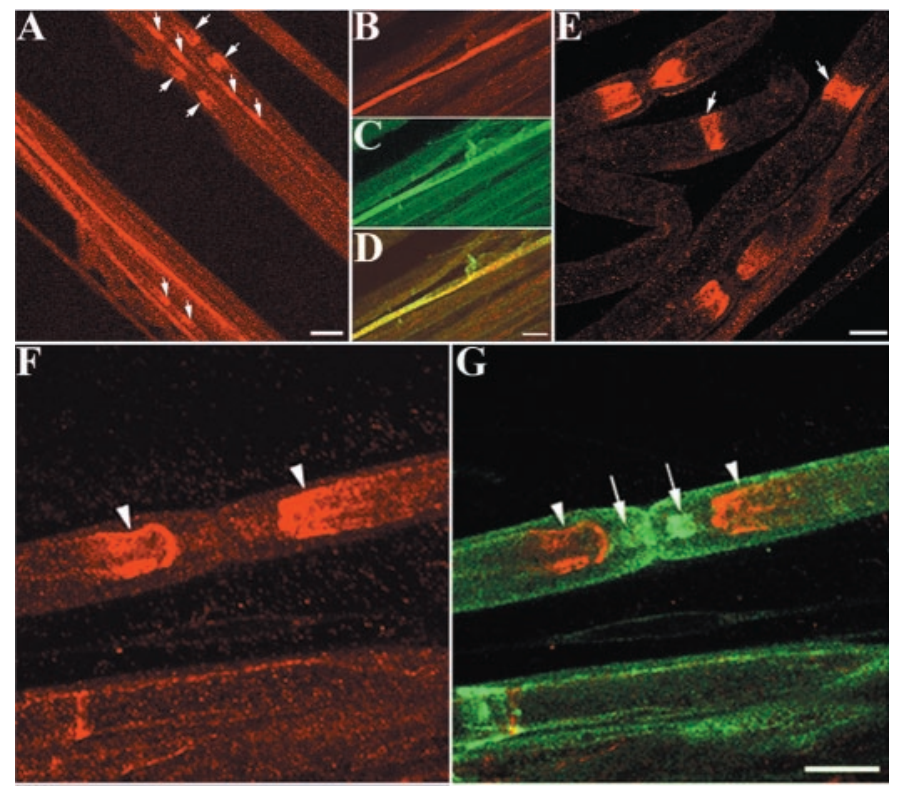

$\mathbf{H}$

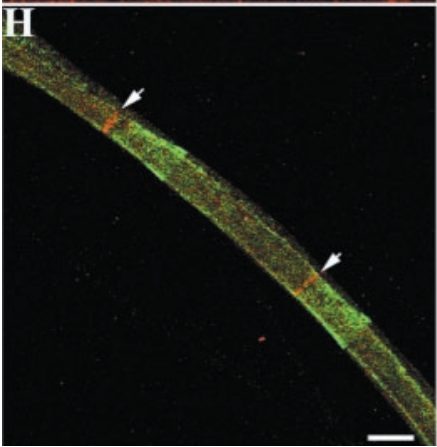

Figure 4. TAG-1 is expressed in the juxtaparanodal region of PNS myelinated fibers in the adult. $A$, In adult sciatic nerve, TAG- 1 continues to be expressed in ensheathing Schwann cells, but it is also detected in myelinated fibers in the region, probably corresponding to the juxtaparanode (arrows). B, TAG-1 is expressed in an ensheathing Schwann cell detected by L1 labeling $(C)$. $D$ is the combined image of $B$ and $C$, which shows that both channels overlap (yellow). E, TAG-1 is also detected in Schmidt-Lanterman incisures (arrows) of myelinated fibers. The juxtaparanodal localization of TAG-1 $(F, G, r e d)$ in adult sciatic nerve was confirmed by double labeling for MAG $(G$, green $)$, which is localized in the paranodal loops of adult myelinated fibers. TAG-1 (arrowheads) appears to be localized adjacent to the paranodal region indicated by MAG labeling (arrows). H, In the internode, TAG-1 (red, arrows) is in register with MAG staining in the incisures (green), which is closest to the axon. $A$, Nine images, $0.9 \mu \mathrm{m}$ apart; $B-D$, six images, $0.7 \mu \mathrm{m}$ apart; $E$, eight images, $0.8 \mu \mathrm{m}$ apart; $F, G$, six images, $0.85 \mu \mathrm{m}$ apart; $H$, five images, $1 \mu \mathrm{m}$ apart. Scale bars: $A, 20 \mu \mathrm{m} ; B-H, 10 \mu \mathrm{m}$.

protein in adult spinal cord membrane fractions highly enriched in myelin (Fig. 6G). TAG-1 was detected in the myelin fraction as a $135 \mathrm{kDa}$ band (lane 1). The $90 \mathrm{kDa}$ TAG-1immunoreactive band was consistently detected in adult tissues (our unpublished results). The same amount of membrane fraction had a limited axolemmal contamination, as shown by the low levels of the $180 \mathrm{kDa}$ L1 isoform detected in lane 3 . High levels of myelin in the extract were indicated by myelin basic protein (MBP) expression (18.5 kDa isoform, lane 4$)$ in a very small amount of sample (1/30 of the amount loaded in lane 1). The presence of TAG-1 protein in the CNS myelin fractions strongly supports its oligodendroglial origin in the juxtaparanodal region.

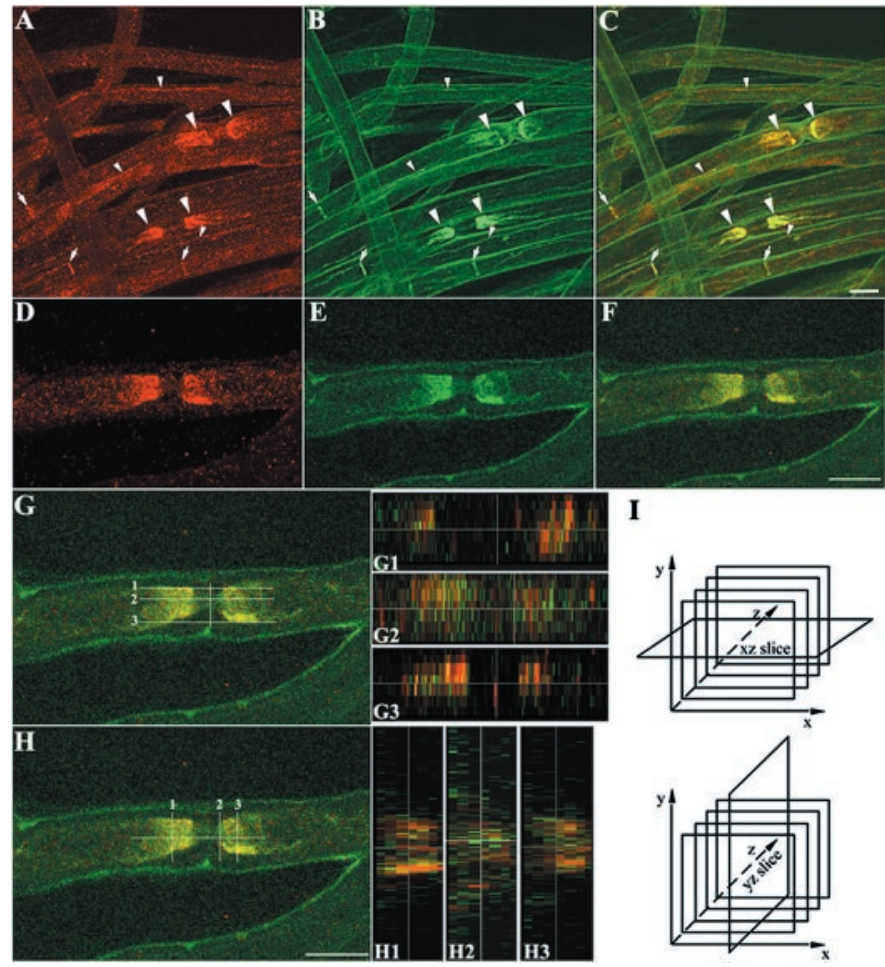

Figure 5. TAG-1 is colocalized with Kv1.1 potassium channels in the PNS myelinated fibers. In teased nerve fibers of adult sciatic nerve, TAG-1 $(A, C, r e d)$ appears to be colocalized with the Kv1.1 potassium channels $(B, C$, green $)$ in myelinated fibers at the juxtaparanodal region (large arrowheads), at the incisures (arrows), and at the inner mesaxon (small arrowheads) because both channels overlap $(C$, yellow). At the juxtaparanode, TAG-1 (D, F, red) colocalization with Kv1.1 potassium channels $(E, F$, green $)$ is shown in a higher magnification in $F$ (yellow). Cross-sectional slices through the image volume showing TAG- $1 / \mathrm{Kv} 1.1$ overlap were performed in the $x z(G)$ and $y z$ plane $(H)$ in the regions shown by numbers. TAG-1 (red) and Kv1.1 potassium channels (green) may be localized in different membranes in the juxtaparanodal region because there is a limited overlap of the two channels in the $x z$ slices $(G 1-G 3)$ and $y z$ slices $(H 1-H 3)$ acquired. I, The planes of the $x z$ and $y z$ slices according to the image sections are demonstrated. $A-C$, Four images, $1 \mu \mathrm{m}$ apart; $D-H$, seven images, $0.4 \mu \mathrm{m}$ apart. Scale bar, $10 \mu \mathrm{m}$.

\section{Distribution of TAG-1 in myelinated fibers of CGT-deficient mice}

The distribution of TAG-1 in myelinated fibers suggests that this adhesion molecule could participate in axoglial interactions. Myelin galactolipids are abundant components of the myelin sheath that are essential for myelin formation and maintenance (Dupree and Popko, 1999). Galactolipid-deficient mice $\left(\mathrm{CGT}^{-/-}\right)$display disrupted axoglial interactions, particularly at the paranodal region of the CNS (Dupree et al., 1999). Oligodendroglial paranodal loops do not reside in close apposition to the axonal membrane in these mutant animals, whereas, the paranodal loops of mutant Schwann cells display significantly less affected interactions with the axon. We performed immunohistochemical analysis in teased nerve fibers from wild-type and CGT mutant sciatic nerves for TAG-1 and potassium channels, which have been shown to be abnormally clustered in the paranodal region in the PNS of the mutants as compared with the juxtaparanodal region in wild-type mice (Dupree et al., 1999). In wild-type mice, TAG-1 (Fig. 7A) was normally colocalized with potassium channels in the juxtaparanodal region (Fig. $7 B$ ). In the CGT mutants, TAG-1 had a different distribution because it appeared in the paranode (Fig. 

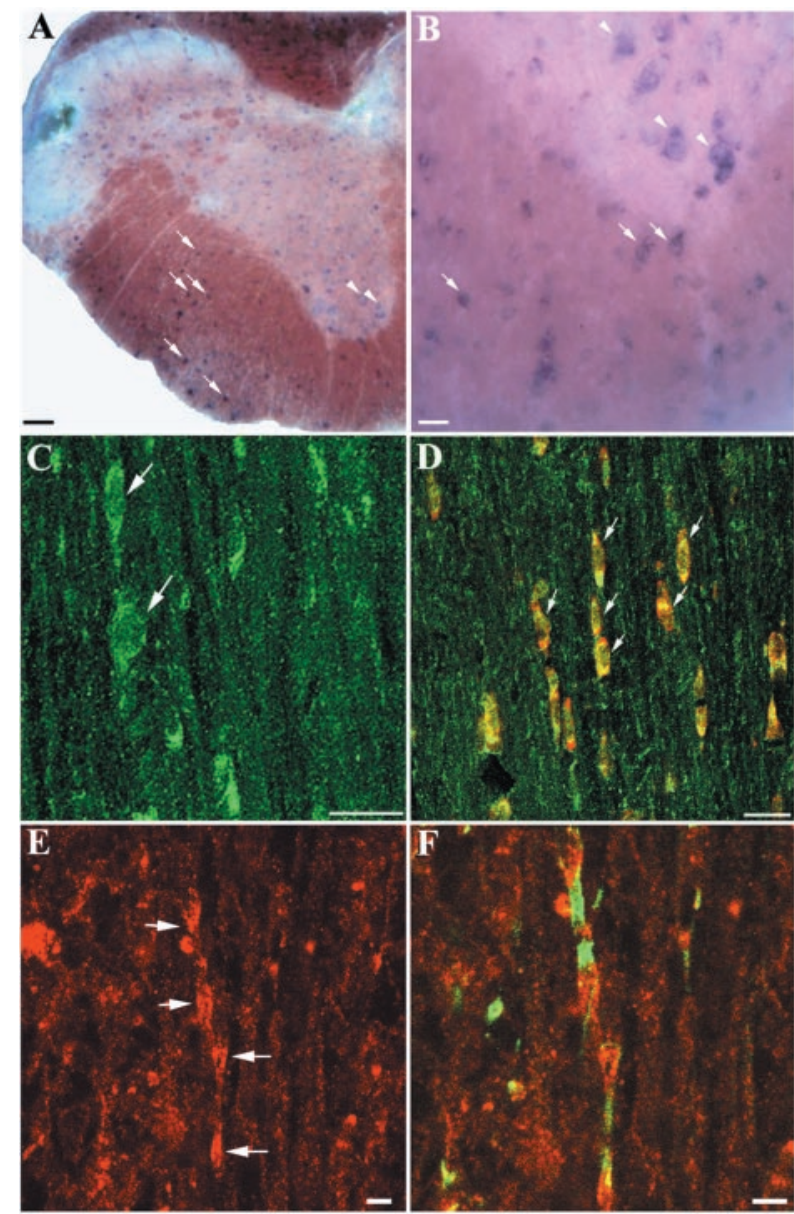

\section{G}

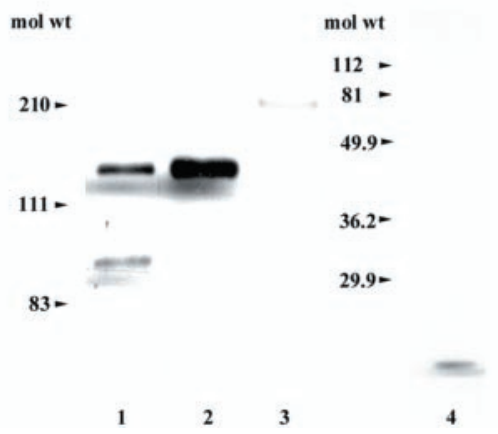

Figure 6. TAG-1 is expressed by oligodendrocytes and accumulates at the juxtaparanodal region. $A$, In adult spinal cord sections, TAG-1 mRNA is expressed in small cells of the white matter (arrows, higher magnification in $B$ ). In the ventral horn TAG-1 is also detected in large, spindleshaped neurons (arrowheads, higher magnification in $B$ ). $C$, In the white matter of adult spinal cord sections, TAG-1 protein is present in the soma of round to oval cells (green, arrows). D, In these cells, TAG-1 (green) colocalizes with APC (red), a marker for oligodendrocytes, as both channels overlap (yellow, arrows). E, TAG-1 also appears in clusters in white matter (red, arrows). F, Sequential labeling for paranodin/Caspr (green) shows that TAG-1 (red) has a discrete distribution and is concentrated in the juxtaparanode of myelinated fibers. $G$, TAG- 1 protein is detected in myelin-rich membrane fractions isolated from adult spinal cord as a $135 \mathrm{kDa}$ band and a $90 \mathrm{kDa}$ adult isoform (lane 1). Whole protein extract from postnatal cerebellum was loaded in lane 2. Low levels of L1 protein are detected in the above myelin fractions $(180 \mathrm{kDa}$ band, lane 3). In these fractions, MBP (18.5 kDa band, lane 4) is abundantly expressed because it is detected in $1 / 30$ of the amount loaded in lanes 1 and 3. $C$, Ten images, $0.4 \mu \mathrm{m}$ apart; $D, 5$ images, $0.4 \mu \mathrm{m}$ apart; $E, F$, 11 images, $0.9 \mu \mathrm{m}$ apart. Scale bars: $A, C, D, 20 \mu \mathrm{m} ; B, E, F, 5 \mu \mathrm{m}$.
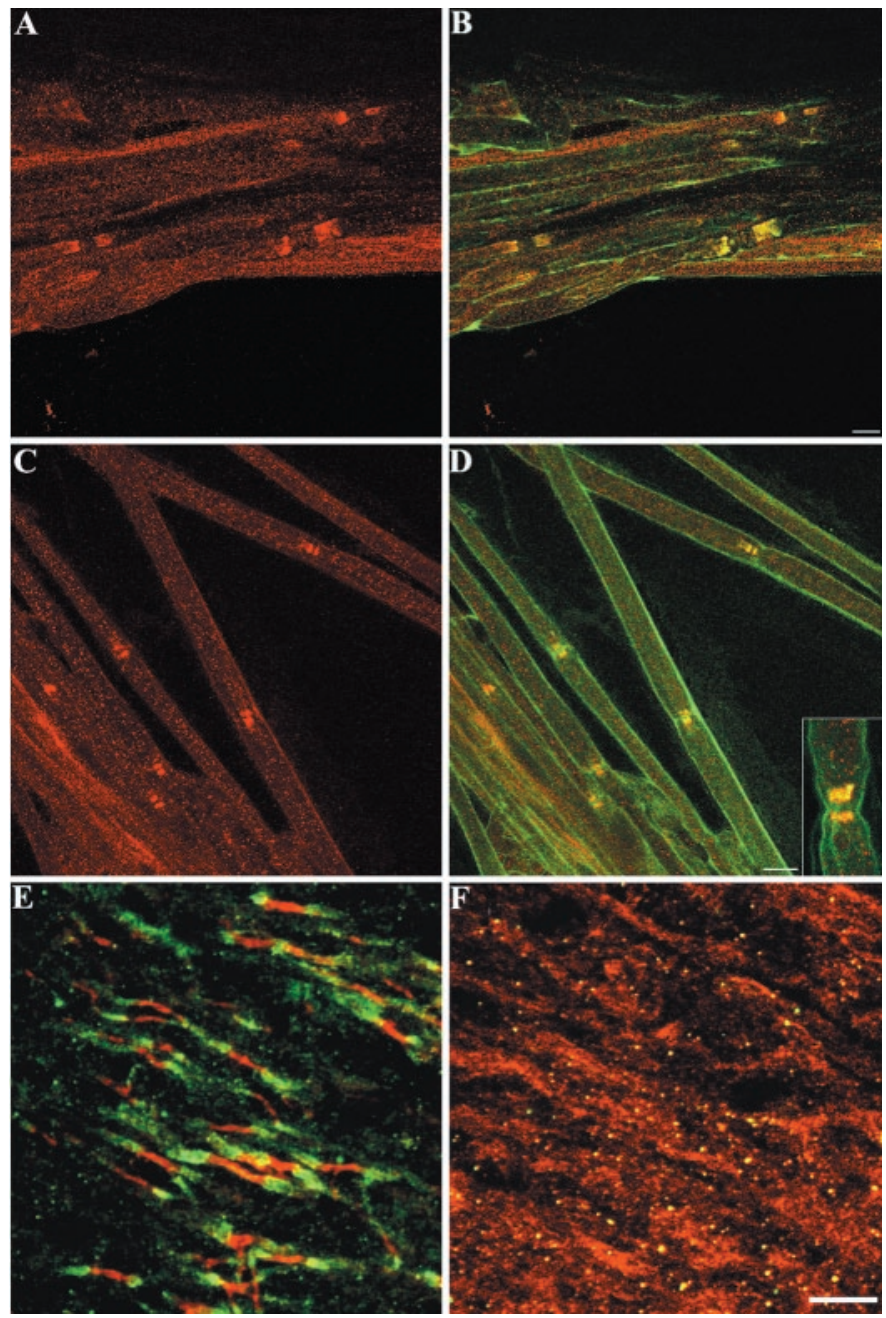

Figure 7. Distribution of TAG-1 in myelinated fibers of CGT-deficient mice. In wild-type sciatic nerve, TAG-1 $(A, B$, red $)$ and Kv1.1 potassium channels $(B$, green $)$ are colocalized in the juxtaparanodal region of myelinated fibers $(B$, yellow $)$. In galactolipid-deficient mice, TAG-1 $(C, D$, red) is detected in the paranodal region similar to Kv1.1 potassium channels $(D$, green $)$ because both channels overlap in this area $(D$, yellow). In the inset of $D$ the colocalization TAG-1 with Kv1.1 potassium channels is shown in a higher magnification. $E$, In the CNS of wild-type animals, TAG-1 (green) is clustered in the juxtaparanodal area of myelinated fibers in spinal cord, in contrast to paranodin/Caspr (red), which is localized in the paranode. $F$, In galactolipid-deficient CNS TAG-1 (green) is reduced to undetectable levels, whereas paranodin/Caspr (red) appears diff use throughout the internodal axolemma. $A, B$, Six images, 0.8 $\mu \mathrm{m}$ apart; $C, D, 7$ images, $0.7 \mu \mathrm{m}$ apart; $E, 22$ images, $0.4 \mu \mathrm{m}$ apart; $F, 14$ images, $0.4 \mu \mathrm{m}$ apart. Scale bars, $10 \mu \mathrm{m}$.

$7 C$ ), where it was colocalized with potassium channels (Fig. 7D). In $>300$ mutant nodes examined, $100 \%$ of them showed paranodal TAG-1 signal. In the spinal cord of wild-type animals, the juxtaparanodal distribution of TAG-1 (Fig. 7E) is shown, in comparison to paranodin/Caspr, which is clustered in the paranodal axolemma. In the CGT mutant mice no TAG-1 labeling was detected, and paranodin/Caspr appeared diff use and not strictly localized in the paranode (Fig. $7 F$ ).

\section{DISCUSSION}

We show in this report that TAG-1 is expressed by Schwann cells and oligodendrocytes. TAG-1 is detected in ensheathing Schwann cells early postnatally. In the adult sciatic nerve, TAG-1 not only 
persists in ensheathing Schwann cells but also appears significantly concentrated in the juxtaparanodal region of myelinated fibers. In the adult spinal cord, TAG-1 is detected in oligodendrocytes and is also clustered in the juxtaparanodal region of myelinated fibers. In mice that are incapable of synthesizing the myelin galactolipids (Coetzee et al., 1996) and which as a result have paranodal loops that do not make normal connections with the axons (Dupree et al., 1998), the juxtaparanodal distribution of TAG-1 is dramatically altered. Taken together, these results point to a putative involvement of TAG-1 in axoglial interactions in the juxtaparanodal region of myelinated fibers. Several aspects of TAG-1 expression in glial cells and its functional implications will be discussed in turn.

\section{TAG-1 expression in myelinated fibers}

TAG-1 is the first IgSF molecule identified in the region of the node of Ranvier in myelinated fibers that is colocalized with Shaker-type Kv1.1 potassium channels normally clustered in the juxtaparanodal axolemma (Wang et al., 1993). In this area, the axonal and glial cell membranes are in close apposition and the exact origin of TAG-1 expression was difficult to determine. However, we present evidence that supports a glial origin of TAG-1 in the juxtaparanodal region. TAG-1 is expressed by Schwann cells and oligodendrocytes and it also exists in CNS myelin fractions. In addition, detailed confocal image analysis suggests that TAG-1 and Shaker-type Kv1.1 potassium channels may be localized in different membranes in the PNS; therefore, we propose that TAG-1 may be clustered in the myelin sheath that apposes the juxtaparanodal axolemma. However, we cannot exclude the possibility that TAG-1 is localized in the juxtaparanodal axolemma and the separation of TAG-1 and potassium channel signals in the cross-sectional analysis (Fig. 5) is attributable to resolution limits of confocal microscopy. In the internodal region of PNS myelinated fibers, TAG-1 is also present in the inner aspect of the Schmidt-Lanterman incisures, which apposes the axonal membrane and in the inner mesaxon. Because TAG-1 coincides significantly with axolemmal Kv1.1 potassium channels in these sites, it might participate in the internodal distribution of these channels (for review, see Arroyo and Scherer, 2000). During development, TAG-1 is first detected within the second postnatal week in the juxtaparanodal region in both the CNS and PNS (our unpublished results) and appears to coincide temporally with potassium channel clustering in this region (Wang et al., 1995; Vabnick et al., 1999). In the CNS, TAG-1 expression in oligodendrocytes might require a neuronal signal because we were unable to detect either TAG-1 protein in oligodendroglial cell lines or TAG-1 mRNA in primary oligodendroglial cultures (our unpublished results).

We examined the localization of TAG-1 in CGT-deficient mice, which are incapable of synthesizing the myelin galactolipids galactocerebroside (GalC) and sulfatide (Coetzee et al., 1996). These animals display paranodal loops that do not make normal connections with the axon as demonstrated by the absence of transverse bands, which are regularly arrayed densities that traverse the periaxonal space between the lateral loops and the axolemma (Dupree et al., 1998; Dupree and Popko, 1999). As a consequence, potassium channels are abnormally available to the extracellular milieu (Dupree et al., 1998; Dupree and Popko, 1999), and paranodin/Caspr is distributed diffusely in the internodal axolemma (Dupree et al., 1999). In addition, Caspr2, another member of the neurexin superfamily, is not properly localized in the juxtaparanodal region of the fibers in these mutants (Poliak et al., 2001)

The observed morphological abnormalities at the paranode are significantly more severe in the CNS than the PNS of the CGT mutants. Interestingly, we have observed that the juxtaparanodal localization of TAG-1 does not occur in the CNS of $\mathrm{CGT}^{-/-}$ animals, whereas the protein is abnormally clustered in the paranodal region in the PNS. These data raise the intriguing possibility that TAG-1 localization in the juxtaparanode mediates the normal axoglial interactions in this region and that the altered localization of TAG-1 in $\mathrm{CGT}^{-/-}$animals contributes to the disrupted axoglial interactions observed in these mutants.

GalC and sulfatide, which are the prominent type of abundant glycosphingolipids in the myelin sheath (Norton and Cammer, 1984), have been found associated with the GPI-linked proteins contactin/F3 and NCAM 120 in detergent-insolubleglycospingolipid-enriched complexes (DIGs) isolated from myelin of adult brain (Kramer et al., 1997). The glycolipid content of Schwann cell DIGs has not been reported. DIGs, which are organized as raft-like microdomains in living membranes, are used as the intracellular sorting mechanism of GPI-linked proteins in mammalian cells (for review, see Muniz and Riezman, 2000). Furthermore, TAG-1 has recently been detected in DIGs isolated from primary cerebellar cultures (Kasahara et al., 2000; Prinetti et al., 2001). Thus, in glial cells the myelin galactolipids could be essential for the targeting of GPI-linked TAG-1 to the juxtaparanodal area, possibly through DIGs. An alternative possibility is that TAG-1 localization in the juxtaparanodal region might require the tight axoglial contact normally displayed in the paranodal region. The severely abnormal axoglial interactions observed in the CNS of CGT mutants might disrupt the routing or retention of the TAG-1 protein to the juxtaparanodal area, such that the lack of TAG-1 localization in this region might be secondary to the disrupted axoglial interactions present in the CGT mutants.

The molecules that TAG-1 associates with in the juxtaparanodal region of the node of Ranvier are unknown at the moment. Our data taken together indicate that myelinating glial cells likely express the TAG-1 that is detected in this region. At the same time, TAG- 1 is expressed by a number of adult neurons. Thus, it is possible that TAG-1 of glial origin interacts with TAG-1 of neuronal origin in the juxtaparanodal region.

Caspr2 is colocalized with Shaker-type Kv1.1 potassium channels in the juxtaparanodal axolemma and appears to be associated with them (Poliak et al., 1999). The clustering of potassium channels in the juxtaparanode requires contact by overlying glial cells (for review, see Rasband and Shrager, 2000). An association of TAG-1 and Caspr2, which could mediate glial control of potassium channel distribution in the juxtaparanodal region of myelinated fibers, is possible. TAG-1 is the first IgSF member identified that appears to be localized in the same region with potassium channels and Caspr2 (our unpublished observations), and it presents an altered distribution in the CGT mutants where the axoglial interactions are affected and as a result potassium channels and Caspr2 are not properly localized in the juxtaparanodal region (Dupree et al., 1999; Poliak et al., 2001)

\section{TAG-1 expression by ensheathing Schwann cells}

Ensheathing Schwann cells express high levels of TAG-1 during development and in the adult, suggesting that TAG-1 may participate in the organization and maintenance of unmyelinated fibers by promoting contact of Schwann cells with axons. In 
unmyelinated fibers, TAG-1 may mediate its actions through a heterophilic mechanism that could involve L1, a known binding partner of TAG-1 (Rader et al., 1996; Malhotra et al., 1998). In L1-deficient mice the structure of sensory unmyelinated fibers is severely disturbed (Dahme et al., 1997; Haney et al., 1999). Studies with these animals have shown that axonal L1 maintains sensory axon-Schwann cell ensheathment through binding to a yet unknown heterologous ligand expressed in the apposed Schwann cell membrane (Haney et al., 1999). TAG-1 localized in ensheathing Schwann cells could be such a ligand for L1. Another possible TAG-1 ligand in these fibers may be Nr-CAM (Suter et al., 1995), which, apart from its nodal distribution in myelinated axons, is also expressed in unmyelinated axons (Davis et al., 1996).

In summary, we provide evidence that TAG-1, previously thought to be a neuronal specific adhesion molecule, is one of the few members of the IgSF family of adhesion molecules known to be expressed in mature Schwann cells and oligodendrocytes. In the PNS, TAG-1 is expressed by ensheathing Schwann cells and as such might play a role in axoglial interactions of unmyelinated fibers. In myelinated fibers, TAG-1 is the first IgSF molecule detected in the juxtaparanodal region in the CNS and PNS. The localization of TAG-1 in myelinated fibers, possibly controlled by myelin galactolipids, might also contribute to important axoglial interactions. Alternatively, the establishment of normal connections of paranodal loops with the axon may be a prerequisite for the proper distribution of TAG-1 in the juxtaparanodal region. Together, these data suggest that TAG-1 might serve as an important cell adhesion molecule for the organization and the maintenance of the juxtaparanode.

\section{REFERENCES}

Arroyo EJ, Scherer SS (2000) On the molecular architecture of myelinated fibers. Histochem Cell Biol 113:1-18.

Arroyo EJ, Xu YT, Zhou L, Messing A, Peles E, Chiu SY, Scherer SS (1999) Myelinating Schwann cells determine the internodal localization of Kv1.1, Kv1.2, Kvbeta2, and Caspr. J Neurocytol 28:333-347.

Bally-Cuif L, Wassef M (1994) Ectopic induction and reorganization of Wnt-1 expression in quail/chick chimeras. Development 120:33793394.

Bhat RV, Axt KJ, Fosnaugh JS, Smith KJ, Johnson KA, Hill DE, Kinzler KW, Baraban JM (1996) Expression of the APC tumor suppressor protein in oligodendroglia. Glia 2:169-174.

Blanchard AD, Sinanan A, Parmantier E, Zwart R, Broos L, Meijer D, Meier C, Jessen KR, Mirsky R (1996) Oct-6 (SCIP/Tst-1) is expressed in Schwann cell precursors, embryonic Schwann cells, and postnatal myelinating Schwann cells: comparison with Oct-1, Krox-20, and Pax-3. J Neurosci Res 46:630-640.

Brophy P (2001) Axoglial junctions: separate the channels or scramble the message. Curr Biol 11:R555-7.

Chirgwin JM, Przybyla AE, MacDonald RJ, Rutter WJ (1979) Isolation of biologically active ribonucleic acid from sources enriched in ribonuclease. Biochemistry 18:5294-5299.

Coetzee T, Fujita N, Dupree J, Shi R, Blight A, Suzuki K, Popko B (1996) Myelination in the absence of galactocerebroside and sulfatide: normal structure and abnormal function and regional instability. Cell 86:209-219.

Dahme M, Bartsch U, Martini R, Anliker B, Schachner M, Mantei N (1997) Disruption of the mouse L1 gene leads to malformations of the nervous system. Nat Genet 17:346-349.

Davis JQ, Lambert S, Bennett V (1996) Molecular composition of the node of Ranvier: identification of ankyrin-binding cell adhesion molecules neurofascin (mucin+/third FNIII domain-) and Nr-CAM at nodal axon segments. J Cell Biol 135:1355-1367.

Dodd J, Morton SB, Karagogeos D, Yamamoto M, Jessell TM (1988) Spatial regulation of axonal glycoprotein expression on subsets of embryonic spinal neurons. Neuron 1:105-116.

Dupree JL, Popko B (1999) Genetic dissection of myelin galactolipid function. J Neurocytol 28:271-279.

Dupree JL, Coetzee T, Blight A, Suzuki K, Popko B (1998) Myelin galactolipids are essential for proper node of Ranvier formation in the CNS. J Neurosci 18:1642-1649.
Dupree JL, Girault JA, Popko B (1999) Axoglial interactions regulate the localization of axonal paranodal proteins. J Cell Biol 147:1145-1152.

Einheber S, Zanazzi G, Ching W, Scherer S, Milner TA, Peles E, Salzer JL (1997) The axonal membrane protein Caspr, a homologue of neurexin IV, is a component of the septate-like paranodal junctions that assemble during myelination. J Cell Biol 139:1495-1506.

Furley AJ, Morton SB, Manalo D, Karagogeos D, Dodd J, Jessell TM (1990) The axonal glycoprotein TAG-1 is an immunoglobulin superfamily member with neurite outgrowth-promoting activity. Cell 61:157-170.

Haney CA, Sahenk Z, Li C, Lemmon VP, Roder J, Trapp BD (1999) Heterophilic binding of L1 on unmyelinated sensory axons mediates Schwann cell adhesion and is required for axonal survival. J Cell Biol 146:1173-1184

Huber LA, Madison DL, Simons K, Pfeiffer SE (1994) Myelin membrane biogenesis by oligodendrocytes. Developmental regulation of low molecular weight GTP-binding proteins. FEBS Lett 347:273-278.

Jessen KR, Mirsky R (1991) Schwann cell precursors and their development. Glia 4:185-194.

Karagogeos D, Morton SB, Casano F, Dodd J, Jessell TM (1991) Developmental expression of the axonal glycoprotein TAG-1: differential regulation by central and peripheral neurons in vitro. Development 112:51-67.

Kasahara K, Watanabe K, Takeuchi K, Kaneko H, Oohira A, Yamamoto T, Sanai Y (2000) Involvement of gangliosides in GPI-anchored neuronal cell adhesion molecule TAG-1 signaling in lipid rafts. J Biol Chem 275:34701-34709.

Kramer EM, Koch T, Niehaus A, Trotter J (1997) Oligodendrocytes direct glycosyl phosphatidylinositol-anchored proteins to the myelin sheath in glycosphingolipid-rich complexes. J Biol Chem 272:8937-8945.

Kreider BQ, Messing A, Doan H, Kim SU, Lisak RP, Pleasure DE (1981) Enrichment of Schwann cell cultures from neonatal rat sciatic nerve by differential adhesion. Brain Res 207:433-444.

Malhotra JD, Tsiotra P, Karagogeos D, Hortsch M (1998) Cis-activation of L1-mediated ankyrin recruitment by TAG-1 homophilic cell adhesion. J Biol Chem 273:33354-33359.

Martini R, Schachner M (1986) Immunoelectron microscopic localization of neural cell adhesion molecules (L1, NCAM, and MAG) and their shared carbohydrate epitope and myelin basic protein in developing sciatic nerve. J Cell Biol 103:2439-2448.

Menegoz M, Gaspar P, Le Bert M, Galvez T, Burgaya F, Palfrey C, Ezan P, Amos F, Girault JA (1997) Paranodin, a glycoprotein of neuronal paranodal membranes. Neuron 19:319-331.

Mirsky R, Jessen KR (1996) Schwann cell development, differentiation and myelination. Curr Opin Neurobiol 6:89-96.

Morgan L, Jessen KR, Mirsky R (1991) The effects of cAMP on differentiation of cultured Schwann cells: progression from an early phenotype $(04+)$ to a myelin phenotype (P0+, GFAP-, NCAM-, NGFreceptor-) depends on growth inhibition. J Cell Biol 112:457-467.

Muniz M, Riezman H (2000) Intracellular transport of GPI-anchored proteins. EMBO J 19:10-15.

Norton WT, Cammer W (1984) Isolation and characterization of myelin. In: Myelin (Morell P, ed), pp 147-196. New York: Plenum.

Norton WT, Poduslo SE (1973) Myelination in rat brain: method of myelin isolation. J Neurochem 21:749-757.

Pedraza L, Haung JK, Colman DR (2001) Organizing principles of the axoglial apparatus. Neuron 30:335-344.

Peles E, Salzer JL (2000) Molecular domains of myelinated axons. Curr Opin Neurobiol 5:558-565.

Pigott R, Davies AM (1987) The monoclonal antibody 69A1 recognizes an epitope found on neurones with axons that fasciculate but not on those with non-fasciculating processes. Development 100:489-500.

Poliak S, Gollan L, Martinez R, Custer A, Einheber S, Salzer JL, Trimmer JS, Shrager P, Peles E (1999) Caspr2, a new member of the neurexin superfamily, is localized at the juxtaparanodes of myelinated axons and associates with $\mathrm{K}+$ channels. Neuron 24:1037-1047.

Poliak S, Gollan L, Salomon D, Berglund EO, Ohara R, Ranscht B, Peles E (2001) Localization of Caspr2 in myelinated nerves depends on axon-glia interactions and the generation of barriers along the axon. J Neurosci 21:7568-7575.

Prinetti A, Prioni S, Chigorno V, Karagogeos D, Tettamanti G, Sonnino S (2001) Immunoseparation of sphingolipid-enriched membrane domains enriched in Src family protein tyrosine kinases and in the neuronal adhesion molecule TAG-1 by anti-GD3 ganglioside monoclonal antibody. J Neurochem 78:1162-1167.

Rader C, Kunz B, Lierheimer R, Giger RJ, Berger P, Tittmann P, Gross $\mathrm{H}$, Sonderegger $\mathrm{P}$ (1996) Implications for the domain arrangement of axonin-1 derived from the mapping of its $\mathrm{NgCAM}$ binding site. EMBO J 159:2056-2068.

Rasband MN, Shrager P (2000) Ion channel sequestration in central nervous system axons. J Physiol (Lond) 525:63-73. 
Rathjen FG, Schachner M (1984) Immunocytological and biochemical characterization of a new neuronal cell surface component (L1 antigen) which is involved in cell adhesion. EMBO J 3:1-10.

Rios JC, Melendez-Vasquez CV, Einheber S, Lustig M, Grumet M, Hemperly J, Peles E, Salzer JL (2000) Contactin-associated protein (Caspr) and contactin form a complex that is targeted to the paranodal junctions during myelination. J Neurosci 22:8354-8364.

Salzer JL (1997) Clustering sodium channels at the node of Ranvier: close encounters of the axon-glia kind. Neuron 18:843-846.

Suter DM, Pollerberg GE, Buchstaller A, Giger RJ, Dreyer WJ, Sonderegger P (1995) Binding between the neural cell adhesion molecules axonin-1 and $\mathrm{Nr}-\mathrm{CAM} /$ Bravo is involved in neuron-glia interaction. J Cell Biol 131:1067-1081.

Tait S, Gunn-Moore F, Collinson JM, Huang J, Lubetzki C, Pedraza L, Sherman DL, Colman DR, Brophy PJ (2000) An oligodendrocyte cell adhesion molecule at the site of assembly of the paranodal axoglial junction. J Cell Biol 150:657-666.

Vabnick I, Trimmer JS, Schwarz TL, Levinson SR, Risal D, Shrager P (1999) Dynamic potassium channel distributions during axonal development prevent aberrant firing patterns. J Neurosci 19:747-758.

Wang H, Kunkel DD, Martin TM, Schwartzkroin PA, Tempel BL (1993) Heteromultimeric $\mathrm{K}+$ channels in terminal and juxtaparanodal regions of neurons. Nature 365:75-79.

Wang H, Allen ML, Grigg JJ, Noebels JL, Tempel BL (1995) Hypomyelination alters $\mathrm{K}+$ channel expression in mouse mutants shiverer and Trembler. Neuron 15:1337-1347.

Yamamoto M, Boyer AM, Crandall JE, Edwards M, Tanaka H (1986) Distribution of stage-specific neurite-associated proteins in the developing murine nervous system recognized by a monoclonal antibody. J Neurosci 6:3576-3594. 